\title{
Simulation of the Antarctic ice sheet with a three- dimensional polythermal ice-sheet model, in support of the EPICA project. II. Nested high-resolution treatment of Dronning Maud Land, Antarctica
}

\author{
A. Savvin, ${ }^{1}$ R. Greve, ${ }^{1}$ R. Calov, ${ }^{2}$ B. Mügge, ${ }^{1}$ K. Hutter ${ }^{1}$ \\ ${ }^{1}$ Institut für Mechanik, Technische Universität Darmstadt, D-64289 Darmstadt, Germany \\ ${ }^{2}$ Potsdam-Institut für Klimafolgenforschung, Postfach 601203, D-14412 Potsdam, Germany
}

\begin{abstract}
The modern dynamic and thermodynamic state of the entire Antarctic ice sheet is computed for a 242200 year paleoclimatic simulation with the three-dimensional polythermal ice-sheet model SICOPOLIS. The simulation is driven by a climate history derived from the Vostok ice core and the SPECMAP sea-level record. In a $872 \mathrm{~km} \times 436 \mathrm{~km}$ region in western Dronning Maud Land (DML), where a deep ice core is planned for EPICA, new high-resolution ice-thickness data are used to compute an improved bedrock topography and a locally refined numerical grid is applied which extends earlier work (Calov and others, 1998). The computed fields of basal temperature, age and shear deformation, together with the measured accumulation rates, give valuable information for the selection of a drill site suitable for obtaining a high-resolution climate record for the last glacial cycle. Based on these results, a possible drill site at $73^{\circ} 59^{\prime} \mathrm{S}, 00^{\circ} 00^{\prime} \mathrm{E}$ is discussed, for which the computed depth profiles of temperature, age, velocity and shear deformation are presented. The geographic origin of the ice column at this position extends $320 \mathrm{~km}$ upstream and therefore does not leave the DML region.
\end{abstract}

\section{INTRODUGTION}

The European Project for Ice Coring in Antarctica (EPICA) is a European initiative to drill two deep ice cores in East Antarctica. In the first 5 year phase (to December 2000) an ice core is being obtained from Dome Concordia (Dome C) (central East Antarctica, see Fig. 1), an area characterized by low-shear ice flow and a snow-accumulation rate of about $35 \mathrm{~mm}$ w.e. $\mathrm{yr}^{-1}$. It is expected to provide a climate archive covering five entire glacial-interglacial cycles $(500 \mathrm{kyr})$. A further objective is to conduct field studies in the Atlantic sector of East Antarctica as a prerequisite for drilling in Dronning Maud Land (DML) in the second phase of EPICA. In contrast to Dome C, the planned DML core will be focused on rapid climate changes within the last glacial-interglacial cycle $(100 \mathrm{kyr})$ in a region under the influence of South Atlantic precipitation sources and with a much larger accumulation rate.

The position of the DML drill site has not yet been established. In accordance with the aims of the coring, criteria which can be assessed by dynamic/thermodynamic ice-sheet modelling are:

(i) no melt in the entire ice column in order to avoid disturbances to the stratigraphy by meltwater;

(ii) a minimum ice age of $130 \mathrm{kyr}$ in order to cover the entire recent climate cycle;

(iii) a large accumulation rate in order to resolve rapid climate changes on time-scales of decades; and

(iv) from a technical point of view, a small shear strain rate in the borehole (cf. Jouzel and others, 1994).
In an earlier study (Calov and others, 1998), an initial attempt was made to determine an appropriate site for the DML core by modelling the present state of DML using a paleoclimatic simulation of the entire Antarctic ice sheet through two climate cycles, and investigating the model out-

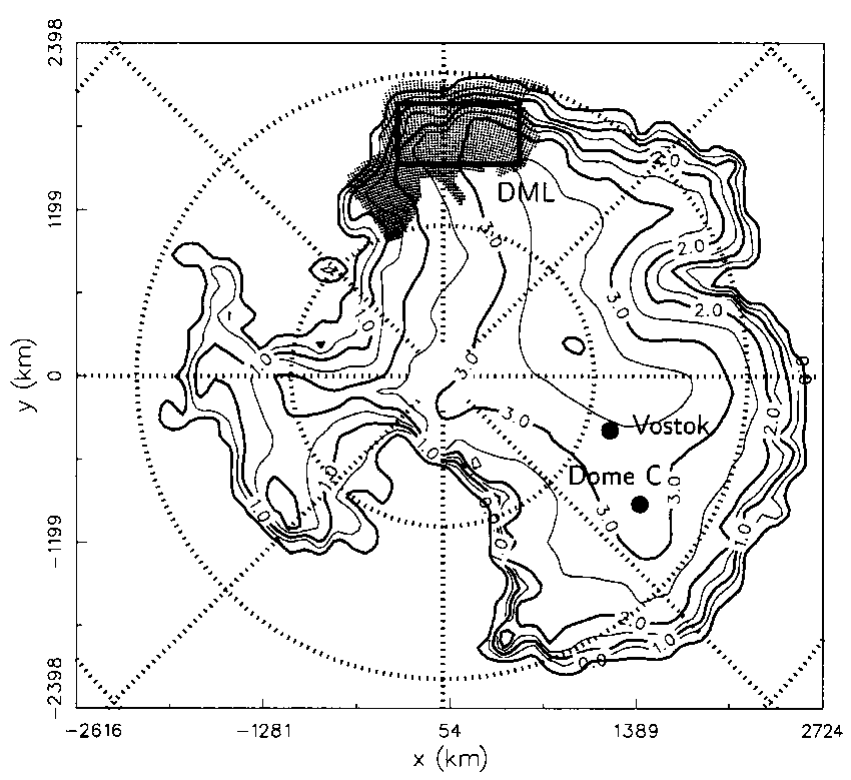

Fig. 1. Surface topography of the modern Antarctic ice sheet by Drewry (1983) (without ice shelves; in km a.s.l., $500 \mathrm{~m}$ contours). The dots in DML denote ice-thickness data points of the recent AWI campaign (see section 2.3), the rectangle within this region is the nested domain for the ice-sheet model. 
put with respect to coring criteria. This led to a preliminary proposal for a drill site at $73^{\circ} 57^{\prime} \mathrm{S}, 03^{\circ} 35^{\prime} \mathrm{W}$. However, due to severe limitations of the input data available at that time and the coarse grid resolution of the model $(109 \mathrm{~km})$ this was only seen as the first step towards an appropriate analysis for the EPICA-DML core. Here we present and discuss a strongly improved simulation based on high-resolution bedrock data in DML, a new accumulation dataset for Antarctica and, on the modelling side, a high-resolution subgrid for DML coupled to the previous coarse grid for the entire ice sheet. The drill-site proposal is adjusted according to these results, and the computed distribution of temperature, age, horizontal velocity and shear deformation is shown for the corresponding ice column.

\section{MODELLING OF DRONNING MAUD LAND}

\subsection{Large-scale ice-sheet model}

The large-scale thermomechanical ice-sheet model SICOPOLIS (SImulation COde for POLythermal Ice Sheets), here used for simulations of the entire Antarctic ice sheet, is based on the continuum-mechanical and thermodynamical theory of polythermal ice sheets in the shallow-ice approximation (Fowler and Larson, 1978; Hutter, 1982, 1993; Greve, 1997b). It computes three-dimensionally the temporal evolution of ice extent, thickness, velocity, temperature, water content and age as a response to external forcing, specified by: (i) the mean annual air temperature above the ice; (ii) the surface mass balance, which is ice accumulation (snowfall) minus ablation (melting, evaporation); (iii) the mean global sea level; and (iv) the geothermal heat flux from below, imposed $5 \mathrm{~km}$ below the ice-bedrock interface in order to account for thermal inertia effects in the lithosphere. Isostasy is treated by a simple local-lithosphererelaxing-asthenosphere model (LeMeur and Huybrechts, 1996), which balances the ice load locally with the buoyancy of the solid lithosphere in the liquid asthenosphere, and accounts for the asthenosphere viscosity by an isostatic time lag $\tau_{\mathrm{V}}$. Ice shelves are ignored, and the ice thickness is set to zero where the ice sheet reaches the coastline. Further general model features are described in greater detail by Greve (1997a) and Greve and others (1998).

The model domain for the entire Antarctic ice sheet consists of a $5341 \mathrm{~km} \times 4796 \mathrm{~km}$ rectangle in the stereographic plane with standard parallel $71^{\circ} \mathrm{S}$, spanned by Cartesian coordinates $x, y$ (the vertical coordinate is $z$ ). Horizontal resolution is $109 \mathrm{~km}$, so that the domain is discretized by $50 \times 45$ gridpoints. Vertical resolution is 51 gridpoints in the cold-ice column, 11 gridpoints in the temperate-ice column (if existing) and 11 gridpoints in the lithosphere column. Time-steps are 2.5 years for the dynamic evolution (ice topography, velocity) and 50 years for the thermodynamic evolution (temperature, water content, age).

\subsection{Nesting for Dronning Maud Land}

Calov and others (1998) used simulation results computed on the $109 \mathrm{~km}$ grid for assessing the present conditions of DML to determine a suitable drill site for the EPICA-DML core. As this coarse resolution only led to $10 \times 9$ gridpoints in the investigated part of DML, it is desirable to carry out simulations at a distinctly higher resolution. This may be achieved by increasing the resolution for the entire ice sheet at the cost
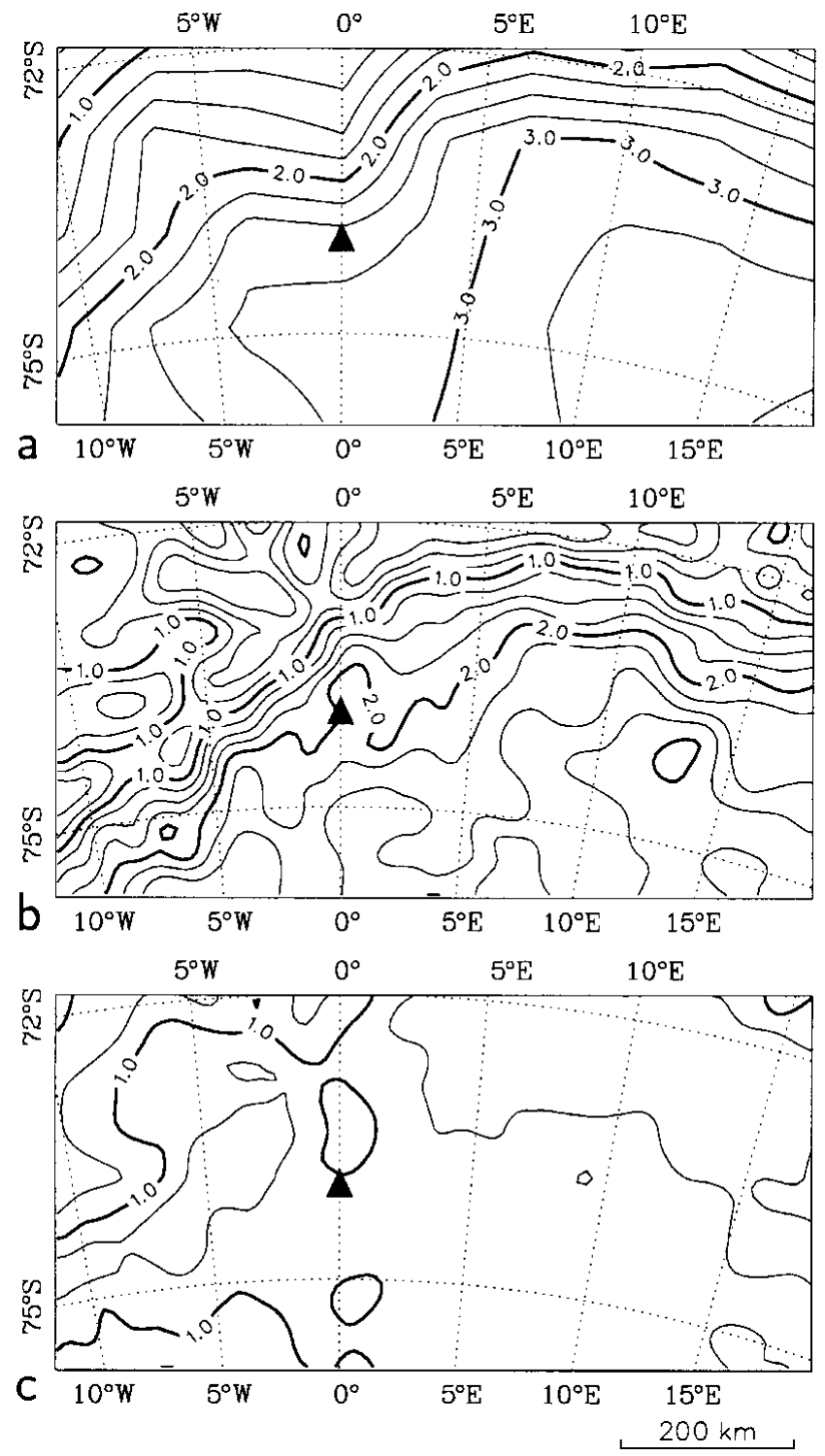

Fig. 2. Nested domain in DML. (a) Modern surface topography by Drewry (1983) (in km a.s.l., $250 \mathrm{~m}$ contours). (b) Modern ice thickness measured by the AWI campaign ( see section 2.3; in km, $250 \mathrm{~m}$ contours). (c) Isostatically relaxed bedrock topography for vanishing ice load (in $\mathrm{km}$ a.s.l., $250 \mathrm{~m}$ contours). The proposed drill site is marked by the full triangle in this and subsequent figures.

of extremely long CPU times. For that reason, we pursued the alternative idea of nesting, that is the Antarctic ice sheet as a whole is still modelled on the $109 \mathrm{~km}$ grid, but for DML a refined subgrid is introduced (Savvin, 1999). On this subgrid, the same model equations as on the coarse grid are solved for the entire ice sheet. Dirichlet-type boundary conditions for the subgrid domain are defined by interpolating the computed coarse-grid fields for surface and bedrock topography, temperature, water content and age onto the margin points of the subgrid. In turn, the subgrid returns the computed topography to the coarse grid at positions where coarse-grid and refined-subgrid points fall together (dynamic feedback). The inclusion of thermodynamic feedbacks from the refined subgrid to the coarse grid was unfavourable for numerical stability and was therefore not employed (Savvin, 1999).

The nested domain chosen is a $872 \mathrm{~km} \times 436 \mathrm{~km}$ rectangle completely covered by the high-resolution ice-thickness data discussed in section 2.3 (Fig. 1). Horizontal resolution is 


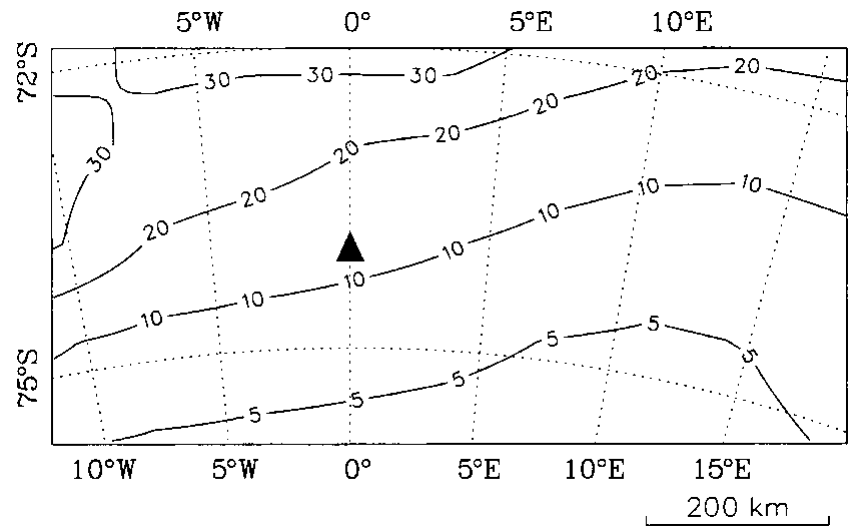

Fig. 3. Modern snow accumulation in DML by Giovinetto, Zwally and Bentley (personal communication, 1997, publica-

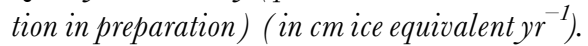

$10.9 \mathrm{~km}$ (refinement factor 10), so the region is now discretized by $81 \times 41$ gridpoints. The time-steps for the refined DML computations are 0.1 year for the dynamic evolution and 1 year for the thermodynamic evolution.

It is clear that a prerequisite for accurate subgrid computations is the accuracy of the boundary conditions provided by the coarse grid. In this context, the $109 \mathrm{~km}$ coarse-grid resolution was sufficient because the simulated overall ice topography (not shown) agrees well with the Drewry (1983) data. Therefore, and so as not to increase the required CPU times drastically, no increased coarsegrid resolution was applied.

The horizontal subgrid resolution of $10.9 \mathrm{~km}$ is less than three times the maximum ice thickness in DML. This is on the edge of applicability of the shallow-ice approximation because normal stress deviators become increasingly important on horizontal scales comparable to the ice thickness. Therefore, in a similar study for the Summit region of the Greenland ice sheet, higher-order algorithms were employed for the nested region which included the normal-stress effects (Greve and others, 1999; Baral, 1999). The inclusion of such algorithms for the nested DML domain will be done in the future.

\subsection{Bedrock topography}

As a part of the DML reconnaissance within the first phase of EPICA, airborne radio-echo-sounding (RES) measurements of the ice thickness at an average resolution of $20 \mathrm{~km}$ were made and evaluated by the Alfred Wegener Institute (AWI) (Steinhage and others, 1999; Figs 1 and 2b). This is of particular importance because the classical maps of the Antarctic ice sheet by Drewry (1983) are based on rather sparse data in DML, so their accuracy does not meet the requirements for the EPICA-DML project. With the new high-resolution ice-thickness data, a much more precise bedrock map was constructed first by interpolating them on the numerical $10.9 \mathrm{~km}$ grid for DML and then subtracting them from Drewry's (1983) already gridded surface topography (Fig. 2a). The isostatically relaxed bedrock topography for vanishing ice load, $z=b_{0}(x, y)$, which is required for the simulations, was finally computed under the assumption that the present bedrock, $z=b(x, y)$, is close to local isostatic equilibrium with its ice load, so that $b_{0}(x, y)=$ $b(x, y)+\left(\rho / \rho_{\mathrm{a}}\right) \times H(x, y)$ (where $H$ is ice thickness, $\rho$ is ice density and $\rho_{\mathrm{a}}$ is asthenosphere density). The result is shown in Figure 2c.

\subsection{Snow accumulation}

Giovinetto, Zwally and Bentley (personal communication, 1997; publication in preparation) have compiled a new accumulation dataset which includes approximately 1700 data points for the entire Antarctic ice sheet. This is a distinct improvement over the 550 data points on which the simulation of Calov and others (1998) was based. For the simulations here, the dataset of Giovinetto, Zwally and Bentley is interpolated onto the coarse $109 \mathrm{~km}$ numerical grid for the entire Antarctic ice sheet as well as onto the refined $10.9 \mathrm{~km}$ DML grid. Figure 3 depicts the resulting accumulation pattern in DML, which shows a clear increase from inland towards the coast.

\subsection{Simulation set-up}

Similar to Calov and others (1998), the present state of the Antarctic ice sheet and DML in particular was modelled as the result of a paleoclimatic simulation from $242200 \mathrm{yr}$ BP to today, initialized by a previous 100000 year steady-state run for the conditions at $242200 \mathrm{yr} \mathrm{BP}$. The simulation is driven by surface-temperature and sea-level histories derived from the Vostok ice core (Jouzel and others, 1993, 1996) and the SPECMAP sea-level record (Imbrie and others, 1984), respectively, and for the present reference state of the surface temperature the parameterizations given by Huybrechts (1993) are used. The accumulation input is based on the modern dataset discussed in section 2.4, modified by a time-dependent factor coupled linearly to the surface-temperature deviation from today (Calov and others, 1998). Surface melting is modelled by a degree-day approach with the parameters $\beta_{\text {snow }}=3 \mathrm{~mm}$ w.e. $\mathrm{d}^{-1} \mathrm{~K}^{-1}$ (snowmelt), $\beta_{\text {ice }}=8 \mathrm{~mm}$ w.e. $\mathrm{d}^{-1} \mathrm{~K}^{-1}$ (ice melt), $P_{\max }=60 \%$ (firn-saturation rate) and $\sigma_{\text {stat }}=5^{\circ} \mathrm{C}$ (standard deviation for statistical air-temperature fluctuations) (Reeh, 1991). Further model parameters are listed in Table 1.

Table 1. Physical parameters used in the simulations

Quantity Value

Gravity acceleration, $g$

Density of ice, $\rho$

Power-law exponent, $n$

Flow-enhancement factor, $E$

Heat conductivity of ice, $\kappa$

Latent heat of ice, $L$

Clausius-Clapeyron gradient, $\beta$

Basal sliding velocity, $\mathbf{v}_{\mathrm{b}}$

Geothermal heat flux, $q_{\text {geo }}$ Isostatic time lag, $\tau_{\mathrm{V}}$

Asthenosphere density, $\rho_{\text {a }}$

Density $\times$ specific heat

of the lithosphere, $\rho_{\mathrm{r}} c_{\mathrm{r}}$

Heat conductivity of the lithosphere, $\kappa_{\mathrm{r}}$
Rate factor, $A\left(T^{\prime}, \omega\right)^{\dagger}$

Specific heat of ice, $c$
Value

$9.8 \mathrm{~m} \mathrm{~s}^{-2}$

$910 \mathrm{~kg} \mathrm{~m}^{-3}$

3

Cold ice: Arrhenius law

Temperate ice: linear dependence on $\omega^{2}$ 5

$9.828 \mathrm{e}^{-0.0057 T[\mathrm{~K}]} \mathrm{W} \mathrm{m}^{-1} \mathrm{~K}^{-1}$

$(146.3+7.253 T[\mathrm{~K}]) \mathrm{J} \mathrm{kg}^{-1} \mathrm{~K}^{-1}$ $335 \mathrm{~kJ} \mathrm{~kg}^{-1}$

$8.7 \times 10^{-4} \mathrm{~K} \mathrm{~m}^{-1}$

Cold base: no-slip

Temperate base: Weertman-type sliding ${ }^{2}$ $54.6 \mathrm{~mW} \mathrm{~m}^{-2}$

3000 years

$3300 \mathrm{~kg} \mathrm{~m}^{-3}$

$2000 \mathrm{~kJ} \mathrm{~m}^{-3} \mathrm{~K}^{-1}$

$3 \mathrm{~W} \mathrm{~m}^{-1} \mathrm{~K}^{-1}$

\footnotetext{
$\dagger$ Homologous temperature $T^{\prime}$ (relative to pressure melting), water content $\omega$ (mass fraction)

* For details see Greve and others (1998).
} 


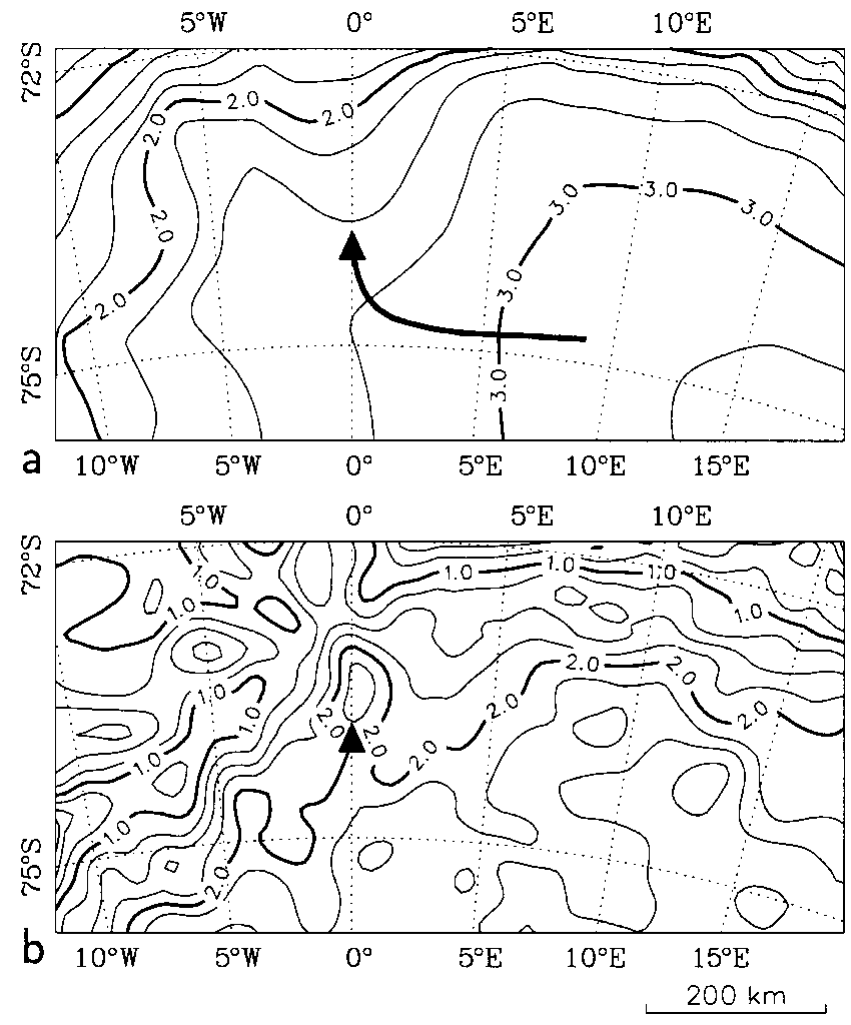

Fig. 4. (a) Simulated modern surface topography (in $\mathrm{km}$ a.s.l., $250 \mathrm{~m}$ contours) and (b) ice thickness (in $\mathrm{km}, 250 \mathrm{~m}$ contours) in DML. The thick line in (a) indicates the simulated geographical origin of the ice column at the proposed drill site.

\section{RESULTS AND IMPLICATIONS FOR THE DML DRILL SITE}

The simulated present state of DML is depicted in Figures 4-8. First, comparison of the simulated ice surface and thickness (Fig. 4) with their data counterparts (Fig. 2) shows good agreement for the surface and excellent agreement for the thickness, for which many of the fine structures are even very well reproduced as a consequence of using the high-resolution input data with the refined subgrid in DML. The main test for the model performance, however, is the surface topography, the good agreement achieved being an essential prerequisite for the suitability of this study in terms of providing model support for the EPICA-DML project. A conspicuous discrepancy between the modelled and the measured ice surface occurs in the northwestern part of the region, where the $2 \mathrm{~km}$ surface contour shows a large bulge towards the coast which is much less pronounced in the data. Further, the divide area in the southwest is not reproduced completely. Nevertheless, these discrepancies are not so large that they might invalidate future results.

The gross direction of the ice flux (Fig. 5a), which points exactly down the surface slope due to the applied shallow-ice approximation (Hutter, 1983), is from southeast to northwest (coastward), and the mass flux increases in the same direction. The very pronounced northward drainage basin around $0^{\circ} \mathrm{E}$ is sustained by the presence of the temperate ice base and, further north, even a basal temperate layer (Fig. 6). Apart from this, cold ice prevails in the region, the basal temperatures being typically a few degrees below pressure melting. The occurrence of bands of temperature contours in the plot, which run along the gridlines, indicates a numerical problem. On the other hand, the age solution (see below),

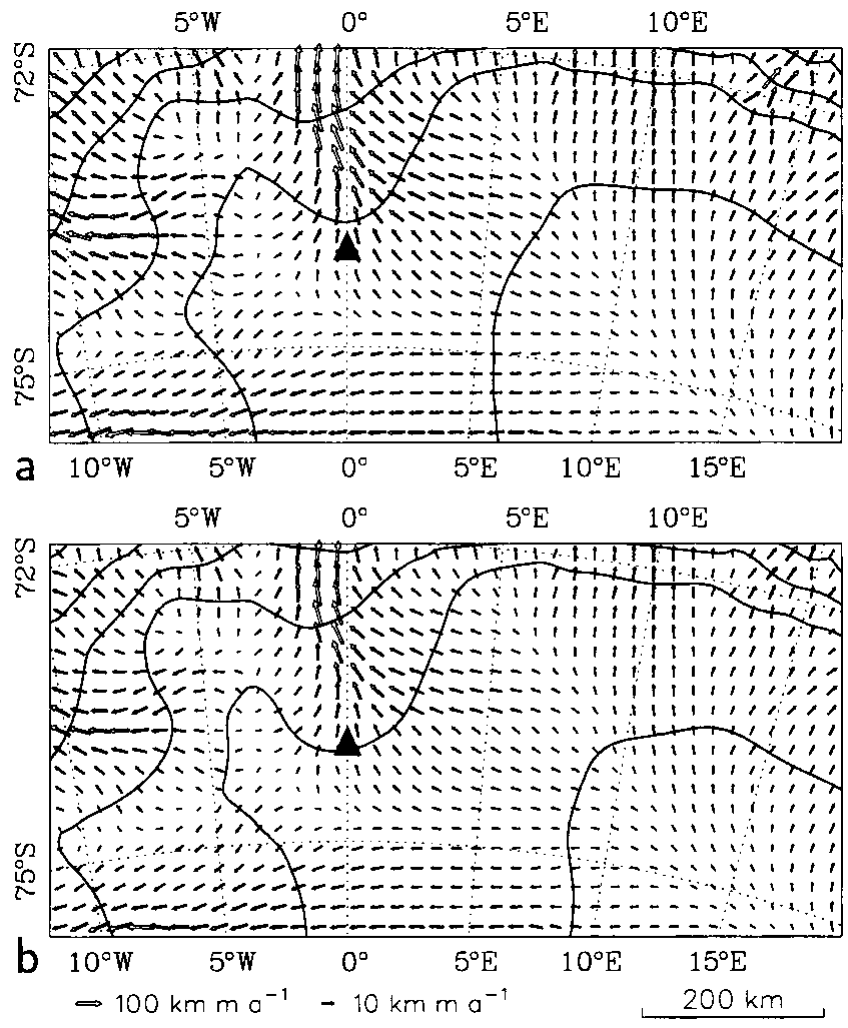

Fig. 5. Simulated mass flux (vertically integrated horizontal velocity) in DML: (a) for modern conditions; (b) at 17.7 kyr BP (Last Glacial Maximum).

which is based on the same type of advection-diffusionproduction equation, does not show such features, so the bands may be a combination of a physically real large gradient and a numerical locking of this gradient to the gridlines.

At glacial-maximum conditions (17.7 kyr BP, Fig. 5b), the simulated ice flux shows smaller absolute values due to the lower ice temperatures; however the general shape of the flow field is the same as for the present. This result is important for the interpretability of any ice core in DML, because strongly varying flow directions over time may induce stratigraphic disturbances such as the strongly inclined layers and overturned folds observed in the Greenland Icecore Project (GRIP) and Greenland Ice Sheet Project Two (GISP2) cores (Alley and others, 1995; Greve and others,

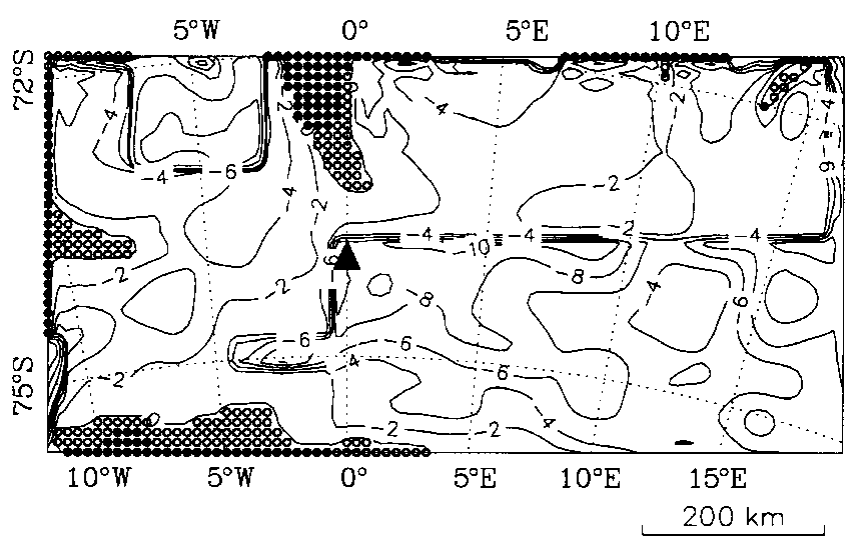

Fig. 6. Simulated modern basal temperature relative to pressure melting (in ${ }^{\circ} \mathrm{C}, 2^{\circ} \mathrm{C}$ contours) in DML. Open circles (full circles) indicate gridpoints where the basal ice is at pressure melting without (with) an overlain layer of temperate ice. 


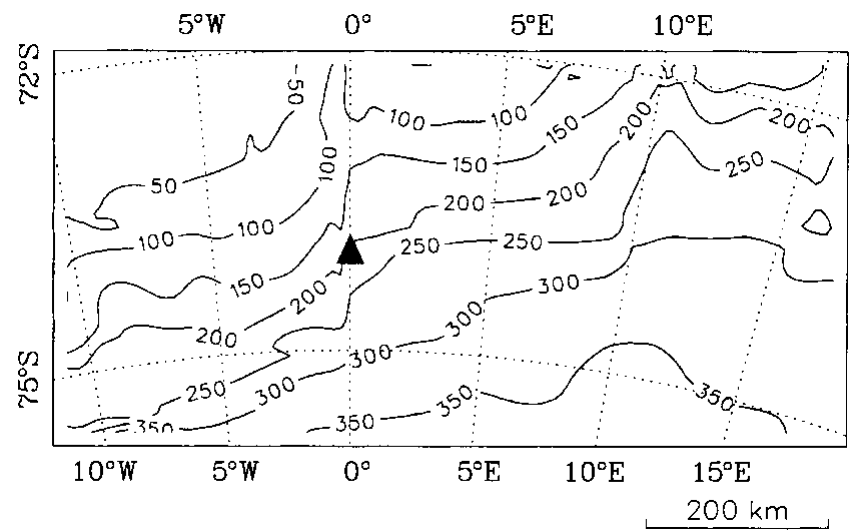

Fig. 7. Simulated modern age at $85 \%$ depth (in kyr, $50 \mathrm{kyr}$ contours) in DML.

1999). However, the simulated preservation of the flow-field shape is strongly linked to the assumed spatial constancy of the accumulation pattern through time (section 2.5) which is not guaranteed in reality, so this result is rather uncertain.

The distribution of the age at $85 \%$ depth, given in Figure 7, shows a mean gradient toward the northwest, and older, deep ice appearing naturally inland. Whereas the simulated ages in the southeast are generally $>300 \mathrm{kyr}$, and thus at least three climatic cycles are covered, close to the coast they are $<100 \mathrm{kyr}$, so that ice columns in this part of the region do not necessarily reach back to the late Eemian.

Together with the mass flux, the horizontal shear deformation $S_{\mathrm{h}}$ at the base, defined by

$$
S_{\mathrm{h}}=\left[\left(\frac{\partial v_{x}}{\partial z}\right)^{2}+\left(\frac{\partial v_{y}}{\partial z}\right)^{2}\right]^{\frac{1}{2}}
$$

(where $v_{x}$ and $v_{y}$ are velocities in the $x$ and $y$ direction, respectively), increases mainly from the southeast to the northwest, with variations of two orders of magnitude (Fig. 8). However, the fine structure of the ice velocity leads to distinct local variations of the basal-shear deformation, so it can vary by an order of magnitude within some $10 \mathrm{~km}$.

In agreement with the aims of the EPICA-DML core, the accumulation field (Fig. 3) makes it desirable to drill as close to the coast in the northwest as possible (criterion (iii) of the Introduction). However, this is limited by criterion (ii) which requires coverage of an entire glacial-interglacial

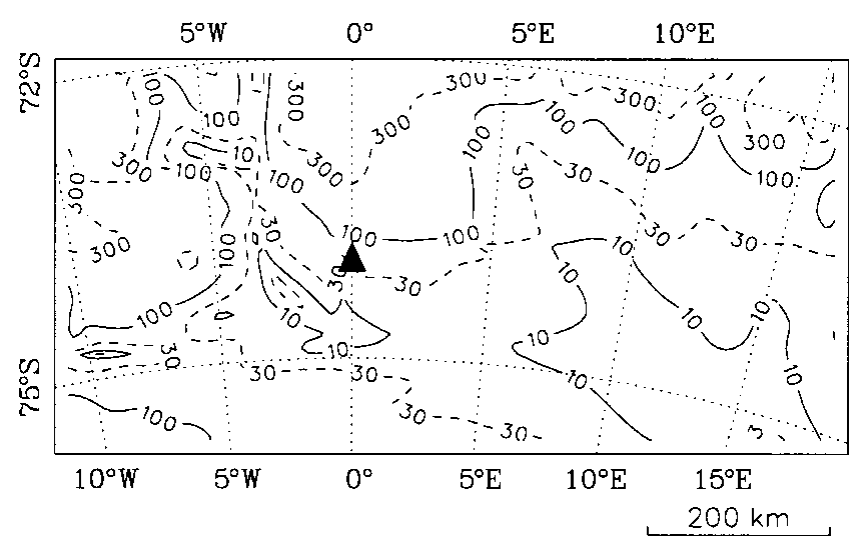

Fig. 8. Simulated modern basal shear deformation (in $10^{-3} \mathrm{yr}^{-1}$ ) in DML.
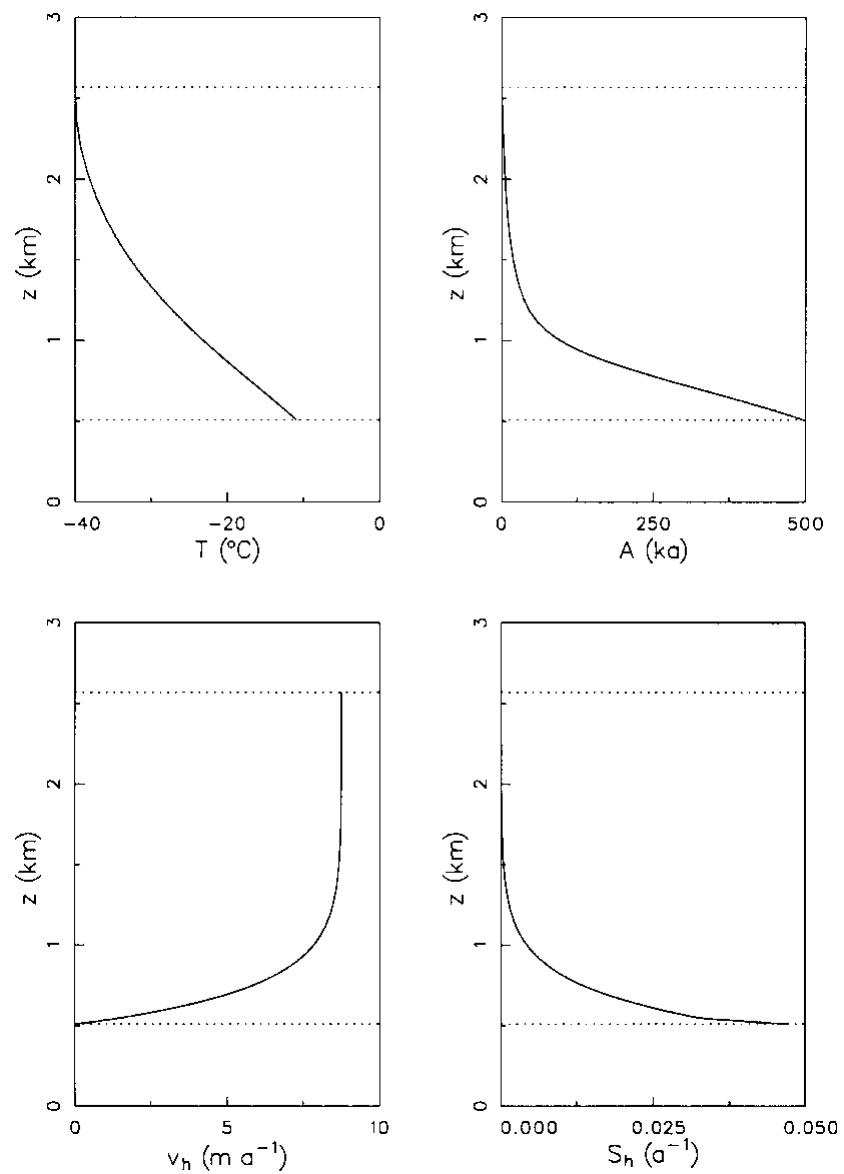

Fig. 9. Proposed drill site in DML at $73^{\circ} 59^{\prime} S, 00^{\circ} 00^{\prime} \mathrm{E}$. Simulated modern depth profiles of temperature $T$, age $A$, horizontal velocity $v_{\mathrm{h}}$ (absolute value $\left(v_{x}^{2}+v_{y}^{2}\right)^{1 / 2}$ ) and shear deformation $S_{\mathrm{h}}$.

cycle. According to Figure 7, this cannot be guaranteed in the northwesternmost part of the considered region.

A reasonable compromise for this tradeoff may be the location at $73^{\circ} 59^{\prime} \mathrm{S}, 00^{\circ} 00^{\prime} \mathrm{E}$. This position is marked in all the DML plots, and its main properties are shown in Figure 9 and Table 2. The accumulation rate is still rather large for Antarctic conditions ( $12.6 \mathrm{~cm}$ ice equiv. $\mathrm{yr}^{-1}$ ), and the age at $85 \%$ depth (215.3 kyr) is large enough by far to contain the last glacial-interglacial cycle. Furthermore, the basal temperature $\left(-10.9^{\circ} \mathrm{C}\right)$ is more than $9^{\circ} \mathrm{C}$ below pressure melting, which leaves sufficient tolerance to fulfill criterion (i) in the whole ice column even if the local geothermal heat flux is somewhat larger than the $54.6 \mathrm{~mW} \mathrm{~m}^{-2}$ we apply here (Table 1). The shear deformation is also relatively small

Table 2. Characteristics of the proposed EPICA-DML drill site at $73^{\circ} 59^{\prime} \mathrm{S}, 00^{\circ} 00^{\prime} \mathrm{E}$

\begin{tabular}{lcc}
\hline & Simulation & Data \\
\hline Surface elevation & $2570 \mathrm{~m}$ a.s.l. & $2580 \mathrm{~m}$ a.s.l. \\
Ice thickness & $2060 \mathrm{~m}$ & $2076 \mathrm{~m}$ \\
Accumulation rate & - & $12.6 \mathrm{~cm} \mathrm{ice} \mathrm{equiv.} \mathrm{yr}^{-1}$ \\
Surface velocity & $8.74 \mathrm{~m} \mathrm{yr}^{-1}$ & - \\
Direction of surface velocity & $-8.2^{\circ}\left(\mathrm{NNW}^{\circ}\right.$ & - \\
Basal temperature & $-10.9^{\circ} \mathrm{C}$ & - \\
Age at 85\% depth & $215.3 \mathrm{kyr}^{-1}$ & - \\
Basal-shear deformation & $0.047 \mathrm{yr}^{-1}$ & - \\
& &
\end{tabular}


(0.047 $\mathrm{yr}^{-1}$ at the base, less above) compared to the maximum values within the DML region, so that criterion (iv) is equally met.

Figure $4 \mathrm{a}$ also shows the geographic origin of the ice in the column at $73^{\circ} 59^{\prime} \mathrm{S}, 00^{\circ} 00^{\prime} \mathrm{E}$. It was computed by tracing the ice particles of the 51 vertical gridpoints back along the threedimensional velocity field until they crossed the ice surface (Mügge, 1998). To this end, the particle-tracing algorithm was run diagnostically with the SICOPOLIS output for the present time-slice only, implying that the evolution of the velocity and topography was neglected. Full coupling between SICOPOLIS and the particle-tracing algorithm with consideration of the time-dependent velocity field has not yet been implemented, this will be done in the near future. Evidently, the ice-origin line calculated in this way extends approximately $320 \mathrm{~km}$ upstream, so the entire $2060 \mathrm{~m}$ thick column was accumulated within the DML domain.

Compared to the previous drill site proposal (Calov and others, 1998; $\left.73^{\circ} 57^{\prime} \mathrm{S}, 03^{\circ} 35^{\prime} \mathrm{W}\right)$, the site considered here $\left(73^{\circ} 59^{\prime} \mathrm{S}, 00^{\circ} 00^{\prime} \mathrm{E}\right)$ is $109 \mathrm{~km}$ further east. The old position still satisfies the four criteria; however, its basal temperature is actually $-5.7^{\circ} \mathrm{C}\left(4.8^{\circ} \mathrm{C}\right.$ below pressure melting), whereas Calov and others (1998) reported $-24.7^{\circ} \mathrm{C}$. As the changes of the accumulation input are small, this huge shift is clearly a consequence of drastically improved knowledge of the basal topography in DML in terms of the gross shape as well as the fine structure, and, directly linked to this, the high numerical resolution which makes efficient use of the fine-structure information. For that reason, the reliability of our new results is distinctly improved.

\section{CONGLUSION AND OUTLOOK}

The present dynamic and thermodynamic state of a $872 \mathrm{~km} \times 436 \mathrm{~km}$ region in western Dronning Maud Land (DML) was computed as the result of a paleoclimatic simulation through two glacial-interglacial cycles using the three-dimensional polythermal ice-sheet model SICOPOLIS. For DML, recent high-resolution radio-echo-sounding icethickness data were used and a nested model with a grid spacing of $10.9 \mathrm{~km}$ was applied. The computed maps of basal temperature, age and shear deformation, together with the accumulation distribution from interpolated field data, contain important information for determining a suitable drill site for the EPICA-DML ice core, the major objective of which is to obtain a high-resolution climate archive for the last glacial-interglacial cycle. Main results are:

(1) The accumulation rate increases from southeast to northwest (toward the coast), which supports a nearcoastal location for the EPICA-DML core.

(2) The near-basal age decreases in the same direction, so that locations too close to the coast do not cover the entire last glacial-interglacial cycle.

(3) Except for a temperate tongue in the north and some minor scattered temperate patches, the basal ice in DML is below pressure melting.

(4) The shear deformation varies by two orders of magnitude in DML with a general coastward increase.

Based on these results, a drill-site at $73^{\circ} 59^{\prime} \mathrm{S}, 00^{\circ} 00^{\prime} \mathrm{E}$ seems favorable. However, the optimum position for the EPICADML core cannot be determined by ice-sheet modelling alone; considerations of atmospheric circulation (Atlantic origin) and chemistry (interpretability of ice-core parameters) must also be included (Jouzel and others, 1994). Ongoing studies of the accumulation distribution in the area and the inclusion of an improved surface-topography dataset (Bamber, 1994; Bamber and Huybrechts, 1996), showing more fine structure than the classical Drewry (1983) data used here, will also result in more refined boundary values. Nevertheless, the results of this study represent a sound basis for further discussion.

\section{ACKNOWLEDGEMENTS}

We thank M. B. Giovinetto, University of Calgary, Alberta, Canada, for providing the accumulation dataset of the Antarctic ice sheet, and H. Miller and D. Steinhage, Alfred Wegener Institute for Polar and Marine Research, Bremerhaven, Germany, for providing the radio-echo-sounding, icethickness data of DML. The comments of A. J. Payne and an anonymous referee helped improve the quality of this paper.

This work is a contribution to the "European Project for Ice Coring in Antarctica" (EPICA), a joint European Science Foundation/European Commission (EG) scientific programme, funded by the EC under the Environment and Climate Programme (1994-98) contract ENV4-CT95-0074 and by national contributions from Belgium, Denmark, France, Germany, Italy, The Netherlands, Norway, Sweden, Switzerland and the United Kingdom. Support for this work from the Deutsche Forschungsgemeinschaft under project No. Hu 412/19-3 is gratefully acknowledged.

\section{REFERENGES}

Alley, R. B., A. J. Gow, S. J. Johnsen, J. Kipfstuhl, D. A. Meese and Th. Thorsteinsson. 1995. Comparison of deep ice cores. Nature, 373(6513), 393-394.

Bamber, J. L. 1994. A digital elevation model of the Antarctic ice sheet derived from ERS-1 altimeter data and comparison with terrestrial measurements. Ann. Glaciol., 20, 48-54.

Bamber, J. L. and P. Huybrechts. 1996. Geometric boundary conditions for modelling the velocity field of the Antarctic ice sheet. Ann. Glaciol., 23, 364-373.

Baral, D. R. 1999. Asymptotic theories of large-scale motion, temperature and moisture distributions in land-based polythermal shields and in floating ice shelves: a critical review and new developments. (Ph.D. thesis, Technische Universität Darmstadt. Institut für Mechanik.)

Calov, R., A. Savvin, R. Greve, I. Hansen and K. Hutter. 1998. Simulation of the Antarctic ice sheet with a three-dimensional polythermal icesheet model, in support of the EPICA project. Ann. Glaciol., 27, 201-206.

Drewry, D. J., ed. 1983. Antartica: glaciological and geophysical folio. Cambridge, University of Cambridge. Scott Polar Research Institute.

Fowler, A. C. and D. A. Larson. 1978. On the flow of polythermal glaciers. I: Model and preliminary analysis. Proc. R. Soc. London, Ser. A, 363(1713), 217-242.

Greve, R. 1997a. Application of a polythermal three-dimensional ice sheet model to the Greenland ice sheet: response to steady-state and transient climate scenarios. f. Climate, 10(5), 901-918.

Greve, R. 1997b. A continuum-mechanical formulation for shallow polythermal ice sheets. Philos. Trans. R. Soc. London, Ser. A, 355(1726), 921-974.

Greve, R., M. Weis and K. Hutter. 1998. Palaeoclimatic evolution and present conditions of the Greenland ice sheet in the vicinity of Summit: an approach by large-scale modelling. Palaeoclimates, 2(2-3), 133-161.

Greve, R., B. Mügge, D. Baral, O. Albrecht and A. Savvin. 1999. Nested high-resolution modelling of the Greenland Summit region. In Hutter, K., Y. Wang and H. Beer, eds. Advances in cold-region thermal engineering and sciences: technological, environmental, and climatological impact. Berlin, etc., Springer-Verlag, 285-306. (Lecture Notes in Physics 533.)

Hutter, K. 1982. A mathematical model of polythermal glaciers and ice sheets. Geophys. Astrophys. Fluid Dyn., 21 (3-4), 201-224.

Hutter, K. 1983. Theoretical glaciology; material science of ice and the mechanics of glaciers and ice sheets. Dordrecht, etc., D. Reidel Publishing Co.; Tokyo, Terra Scientific Publishing Co. 
Hutter, K. 1993. Thermo-mechanically coupled ice-sheet response - cold, polythermal, temperate. f. Glaciol., 39(131), 65-86.

Huybrechts, P. 1993. Glaciological modelling of the Late Cenozoic East Antarctic ice sheet: stability or dynamism? Geogr. Ann., 75A(4), 221-238.

Imbrie, J. and 8 others. 1984. The orbital theory of Pleistocene climate: support from a revised chronology of the marine $\delta^{18} \mathrm{O}$ record. In Berger, A. J. Imbrie, J. Hays, G. Kukla and B. Saltzman, eds. Milankovitch and climate: understanding the response to astronomical forcing. Part 1. Dordrecht, etc., D. Reidel Publishing Co., 269-305. (NATO ASI Series C: Mathematical and Physical Sciences 126.

Jouzel, J. and 16 others. 1993. Extending the Vostok ice-core record of palaeoclimate to the penultimate glacial period. Nature, 364(6436), 407-411.

Jouzel, J., K. Hammer, H. Miller, G. Orombelli, D. Peel and B. Stauffer. 1994. European project for ice coring in Antarctica. Science plan. Gif sur Yvette, CEA/DSM SE Saclay. Laboratoire de Modélisation du Climat et de l'Environnement.

Jouzel, J. and 14 others. 1996. Climatic interpretation of the recently extended
Vostok ice core records. Climate Dyn., 12(8), 513-521.

Le Meur, E. and P. Huybrechts. 1996. A comparison of different ways of dealing with isostasy: examples from modelling the Antarctic ice sheet during the last glacial cycle. Ann. Glaciol., 23, 309-317.

Mügge, B. 1998. Eisalterberechnung im antarktischen Eisschild mit einem Algorithmus zur Teilchenverfolgung. (Diploma thesis, Technische Universität Darmstadt. Institut für Mechanik.)

Reeh, N. 1991. Parameterization of melt rate and surface temperature on the Greenland ice sheet. Polarforschung, 59(3), 1989, 113-128.

Savvin, A.A. 1999. Grenzschichttheorie nichtlinearer Kriechströmungen und ihre Anwendung auf das EPICA-Vorhaben. (Ph.D. thesis, Technische Universität Darmstadt. Institut für Mechanik.

Steinhage, D., U. Nixdorf, U. Meyer and H. Miller. 1999. New maps of the ice thickness and subglacial topography in Dronning Maud Land, Antarctica, determined by means of airborne radio-echo sounding. Ann. Glaciol., 29, 267-272. 